\title{
Assurance ménage et RC privée
}

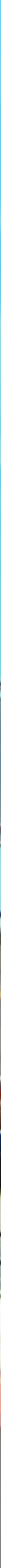

\section{ASSURANCE MÉNAGE ET RC PRIVÉE}

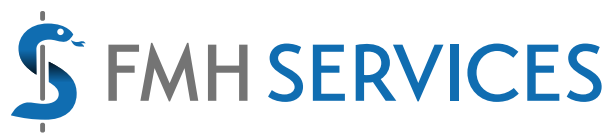

$\square \quad$ J'aimerais recevoir une offre de FMH Services (Insurance) pour une assurance ménage et RC privée, sans frais ni engagement. (Merci de joindre une copie de votre police d'assurance actuelle.)

$\square \quad$ Veuillez m'appeler pour un conseil personnalisé.

Prénom / nom

Adresse

NPA / lieu

Téléphone privé / cabinet

Atteignable le plus facilement

Adresse e-mail

Talon réponse: prière d'envoyer ou de faxer au 0319595010

\section{INSURANCE}

\section{Roth Gygax \& Partner AG}

Moosstrasse 2, 3073 Gümligen

Tél. 0319595000 - Fax 0319595010

mail@fmhinsurance.ch - www.fmhinsurance.ch

Roth Gygax \& Partner AG est une entreprise de conseil indépendante sur le plan juridique et économique recommandée par la société coopérative FMH Services. 